\title{
Start Date and Time of Procedure
}

National Cancer Institute

\section{Source}

National Cancer Institute. Start Date and Time of Procedure. NCI Thesaurus. Code C117529.

The date and time of the beginning of the procedure. 